\title{
Article \\ Socio-Economic Barriers to Adoption of Electric Vehicles in South Africa: Case Study of the Gauteng Province
}

\author{
Mokhele Edmond Moeletsi 1,2,3 (D) \\ 1 Agricultural Research Council-Natural Resources and Engineering, Private Bag X79, \\ Pretoria 0001, South Africa; moeletsim@arc.agric.za or mmoeletsi@hotmail.com; Tel.: +27-12-310-2537; \\ Fax: +27-12-323-1157 \\ 2 Business School, Nelson Mandela University, 2nd Avenue Campus, Summerstrand, \\ Port Elizabeth 6001, South Africa \\ 3 Risk and Vulnerability Science Centre, University of Limpopo, Private Bag X1106, Sovenga, \\ Polokwane 0727, South Africa
}

Citation: Moeletsi, M.E

Socio-Economic Barriers to Adoption of Electric Vehicles in South Africa: Case Study of the Gauteng Province. World Electr. Veh. J. 2021, 12, 167. https://doi.org/10.3390/wevj12040167

Academic Editor: Joeri Van Mierlo

Received: 5 August 2021

Accepted: 13 September 2021

Published: 27 September 2021

Publisher's Note: MDPI stays neutral with regard to jurisdictional claims in published maps and institutional affiliations.

Copyright: (C) 2021 by the author. Licensee MDPI, Basel, Switzerland. This article is an open access article distributed under the terms and conditions of the Creative Commons Attribution (CC BY) license (https:/ / creativecommons.org/licenses/by/ $4.0 /)$.

\begin{abstract}
Electric vehicles (EVs) were introduced into the South African market in 2013, and their adoption rate has been very low. There are limited existing studies covering consumer perceptions towards EVs in Africa and, thus, this study investigated possible socio-economic barriers present in the South African automotive market that impede the adoption or consumer purchase intention of EVs. The survey was conducted in the Gauteng Province in South Africa using questionnaires comprised of Likert-type questions. The analysis was conducted using statistical methods comprising mainly of frequency tables and Chi-squared tests on contingency tables. The findings of the study on barriers to adoption of EVs in the market highlighted the high purchase price, high battery price, and high likelihood for owning a secondary vehicle based on the current circumstances as the main purchase intention barriers that the respondents in the Gauteng Province accentuated. However, generally the willingness to buy EVs was high for a majority of the factors that were presented. With these perceived positive opinions from respondents, it is down to government and private companies to provide a conducive environment for the consumers.
\end{abstract}

Keywords: climate change; electric vehicle technology; transport GHG emissions; low-carbon technology; Cronbach's alpha

\section{Introduction}

Climate change became a global issue towards the end of the 20th century as governments, scientists, and international organizations became aware of the adverse impact that increased greenhouse gases have had on our climate since the start of industrialization [1]. The compounding levels of greenhouse gas (GHG) emissions in the atmosphere are the result of human activities around the world. All main economic activities contribute in one way or another, but the main culprit is the energy sector through combustion of fossil fuel [2]. The transport sector is one of the contributors to increased GHG emissions, with more than $14 \%$ of total global emissions [3,4]. The main problem is that, emissions from this sector are projected to rise over time up to $70 \%$ by 2050 based on the business-as-usual scenario [5].

In the context of what has been discussed in the preceding paragraph on the challenges of ever-increasing carbon emissions, many studies indicate that the need to change the propulsion system and convert to electric vehicles (EVs) presents the world with a solution to attain a sustainable future [6-10]. A lot of research has focused on electrifying passenger cars as they contribute to over $90 \%$ of the transport emissions. Therefore, this class presents an opportunity for massive gains in the fight against the increasing greenhouse gas effect [11]. There are a number of studies all over the world that have shown that conversion to EVs would mitigate GHG emissions from the transport sector $[10,12,13]$. Electric vehicles 
available in the current market differ according to their degree of hybridization, starting with hybrid vehicles with limited battery power to fully-electric vehicles with enhanced battery power, corresponding to varying mitigation potential [14].

The electric vehicle market is in its infancy stage as compared with the internal combustion engine (ICE) market, with very few vehicle manufacturers embarking on producing them on a large scale globally. As stated in Ghasri et al. [15], EVs are perceived as inferior to ICE vehicles mainly due to limited range, low density of recharging stations, high costs of purchase and maintenance, and extremely long recharging times. The reason is that there are still many technological advancements that need to be in place in order for these vehicles to reach the same satisfaction levels of ICE vehicles. Some of the issues include the slow rate of development of the battery technology, with current batteries having low energy density per weight thus posing a dilemma to manufacturers on the battery size and range needed to reduce customer anxiety [16-19]. Pricing of EVs has been another major cause of slow uptake, even though there have been gradual advancements and reduction of costs related to batteries and other parts in recent times [20]. Uptake of electric mobility technology is a challenge, with a number of manufacturers having to abandon their production of electric vehicles due to low market penetration. Everything is dependent on the preparedness of consumers to embrace new technology in the transport sector [18]. The majority of the people are still not aware of electric vehicle technology in the world, and South Africa included. The exception is found in select countries such as Norway, where there is government support for enrolment of EVs enabled by favorable policies [20]. This has led to an exponential increase in EVs on the road worldwide since 2010, with the estimated number exceeding 10 million in 2020 [21].

In South Africa, and Africa in general, there are limited studies which have concentrated on perceptions of consumers on electric vehicles technology. Thus, the aim of this study was to analyze the barriers for the intention to purchase electric vehicles using a structured questionnaire.

\section{Materials and Methods}

\subsection{Study Area}

The study was undertaken in the Gauteng Province of South Africa, which is the smallest province in the country with an area covering $18,178 \mathrm{~km}^{2}$ [22]. The province is home to over 14.7 million people, representing $25.4 \%$ of the national total population, making it the most populous and high-density province in the country. Gauteng Province is the country's main economic hub and currently contributes over $34.3 \%$ to the national gross domestic product (GDP), with most of the activities centered around the City of Johannesburg, City of Tshwane, and City of Ekurhuleni (Figure 1). The electricity generation mix of South Africa is mostly made from fossil fuel, with coal-fired power stations producing close to $90 \%$ of the electricity, making it not an ideal power to charge electric vehicles [23]. 


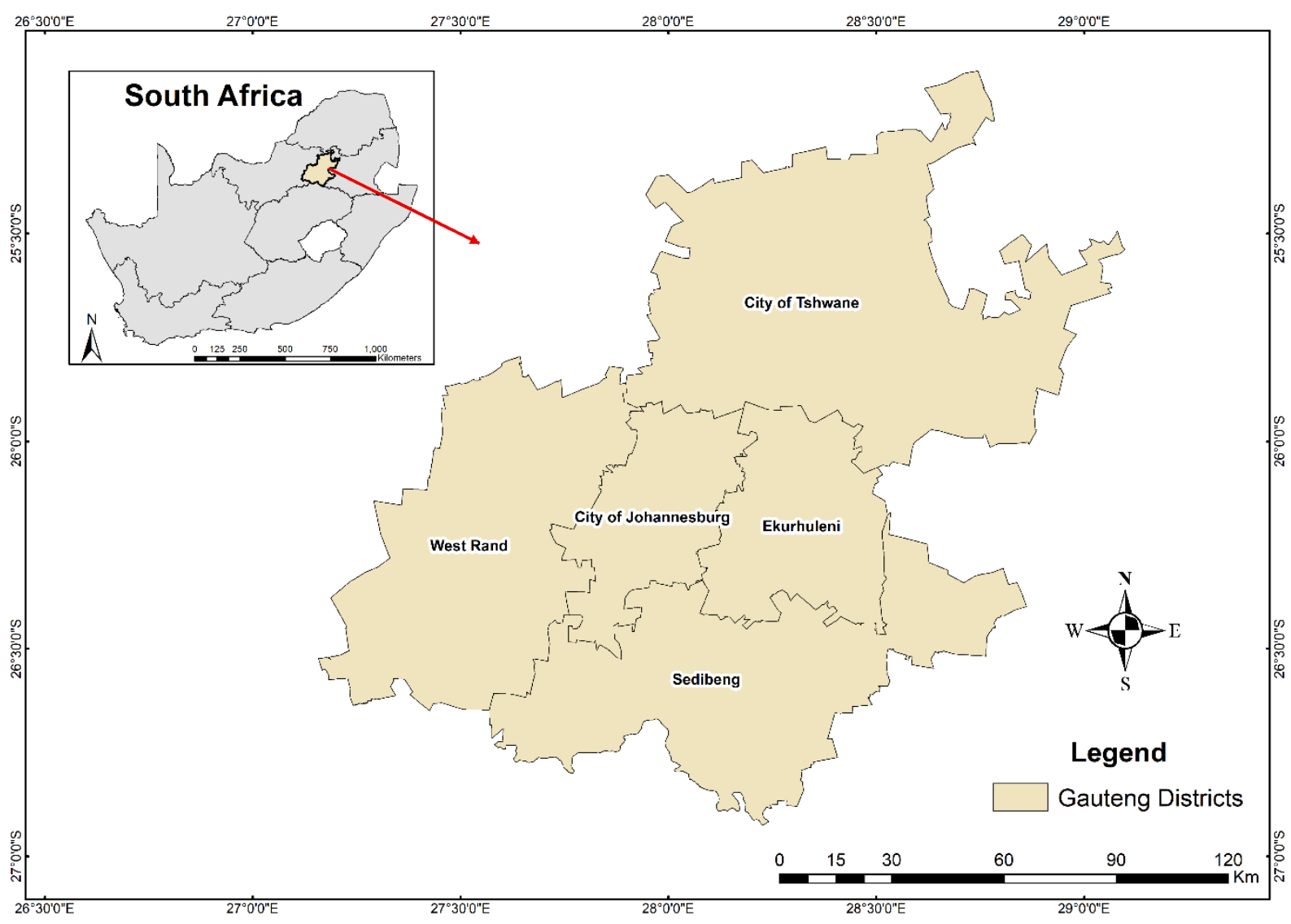

Figure 1. Map showing the position of Gauteng Province and its five districts.

\subsection{Methodology}

The first step in investigating the obstacles for electric vehicle market penetration that can be present in the South African market was to conduct the survey. The Gauteng Province was chosen based on the high number of EVs as well as the infrastructural investment in the province to support electric mobility. Out of the approximately 143 charging stations in South Africa, over 40\% of them are in the Gauteng Province [24,25].

There are a number of ways of conducting a survey and all these approaches have their advantages and disadvantages. Thus, there is a need to carefully choose the right instrument based on the nature of your investigation. The communication instrument in surveys can take any of the following forms: telephonic interviews, web-based survey, self-administered survey, and one-on-one interviews.

In this study, a web-based survey method was used due to low cost, efficiency, and limited time available to conduct the research. The survey was conducted using Survey Monkey facilities "https: / / www.surveymonkey.com/r/electriccars (access on 12 December 2018)" and the survey was run from 24 September to 8 November 2018. The questionnaire web link was spread to the respondents through the use of Facebook, email, and WhatsApp, creating a snowball sampling approach. The survey was made up of 29 questions subdivided into two sections. All the questions were of the multiple-choice format, giving a respondent little latitude to be descriptive. In most of the questions, a Likert-scale approach was used, with questions mostly asking the degree to which the respondent agreed or disagreed with a certain statement. The two main sections present in the questionnaire were as follows [26,27]:

(1) General Information

Demographic information: age, gender, race, education, region of residence, type of dwelling, and property ownership. 
Car ownership: number of cars owned, type of car owned, type of fuel of the car, engine size of the car and kilometers travelled on daily basis.

(2) Adoption of electric cars

Consideration of current purchase of electric cars depending on following traits: electric cars reduce emissions and pollution; no purchases of fuel resulting in money savings; driving range of up to $200 \mathrm{~km}$, the car needs regular charging; charging takes around $8 \mathrm{~h}$; limited quick-charging stations around the country; only compact vehicles in the South African market; warranty of 6 years or more and over 100,000 km; battery cost over ZAR 130,000 $(\approx$ USD 8700 ) out of the warranty and it costs over ZAR 479,000 ( $\approx$ USD 32,300) to buy it.

All the questions had five factors, namely, "very likely", "likely", "neither likely nor unlikely", "unlikely" and "very unlikely".

To check for the reliability or internal consistency of the questionnaire, Cronbach's alpha statistic was used. Cronbach's alpha tests whether Likert-scale type of multiplechoice questions are reliable or consistent [28]. This test statistic measures reliability, which relates to 'how well a test measures what it should' [29]. The equation used is as follows:

$$
\propto=\frac{N \times \bar{c}}{\bar{v}+(N-1) \times \bar{c}}
$$

where $N$ is the number of items, $\bar{c}$ is the average covariance between item-pairs, and $\bar{v}$ is the average variance.

The table below shows how the results are interpreted (Table 1).

Table 1. Interpreting Cronbach's alpha for Likert-scale questions.

\begin{tabular}{cc}
\hline Cronbach's Alpha & Internal Consistency \\
\hline$\alpha \geq 0.9$ & Excellent \\
$0.8 \leq \alpha<0.9$ & Good \\
$0.7 \leq \alpha<0.8$ & Acceptable \\
$0.6 \leq \alpha<0.7$ & Questionable \\
$0.5 \leq \alpha<0.6$ & Poor \\
$\alpha<0.5$ & Unacceptable \\
\hline
\end{tabular}

The results of the Cronbach's alpha test yielded 0.899 , indicating that the survey questions showed a high level of reliability.

Descriptive statistics from the STATISTICA software were used to analyze the data that were collected. The responses to the close-ended survey questions were converted to percentages based on the total number of responses for that particular question that relate to a certain perceived barrier for the adoption of electric cars in South Africa. The biasness of the respondents was then revealed based on the respondents' answers to certain barrier factors. The "very likely" and "likely" responses were mostly grouped together while the "very unlikely" and "unlikely" responses were also aggregated during the analysis and interpretation.

The Chi-square test was used to determine the significance between demographic factors and factors that influenced the absorption of EVs in the market using $5 \%$ and $10 \%$ confidence levels.

\section{Results and Discussion}

A total number of 446 responses were received from 24 September to 8 November 2018, with only 402 respondents able to complete all questions.

\subsection{Basic Information}

The single largest age group of respondents (41\%) comprised those between the ages of 25 and 34, followed by those aged between 35 and 44 with 29.6\% (Table 2). The age group proportions are more or less similar to the ones obtained in the study conducted 
by Zhu [20]. Among the respondents, 49.55\% were female, while $50.45 \%$ were male. In terms of race, close to $90 \%$ of the respondents were black, with the second-highest race of the respondents being white with around $9 \%$. The data representation resembled that of the Gauteng Province Census data, with some minor deviations [30]. The education-levels dynamics of the respondents was significantly different from the one obtained from the 2011 Census, with most respondents having post-graduate qualifications or Bachelor's degrees. Over $85 \%$ of the respondents had post-matric qualifications, compared to only around $18 \%$ obtained from the 2011 census [30]. It could also be noted that most people were from the City of Tshwane (56.7\%), followed by the city of Johannesburg, and the City of Ekurhuleni, with the dominant dwelling settings of a suburb (76\%) and township (20\%). In terms of home ownership, over $47 \%$ of the respondents owned houses in the province, with $43 \%$ renting.

Table 2. Basic information obtained from the respondents.

\begin{tabular}{|c|c|c|}
\hline Type of Information & Categories & Percentage \\
\hline \multirow{7}{*}{ Age group } & $<18$ & $0.45 \%$ \\
\hline & $18-24$ & $15.70 \%$ \\
\hline & $25-34$ & $41.03 \%$ \\
\hline & $35-44$ & $29.60 \%$ \\
\hline & $45-54$ & $8.74 \%$ \\
\hline & $55-64$ & $3.36 \%$ \\
\hline & $65+$ & $1.12 \%$ \\
\hline \multirow{2}{*}{ Gender } & Female & $49.55 \%$ \\
\hline & Male & $50.45 \%$ \\
\hline \multirow{4}{*}{ Race } & Black & $89.01 \%$ \\
\hline & Coloured & $1.12 \%$ \\
\hline & Indian & $1.12 \%$ \\
\hline & White & $8.74 \%$ \\
\hline \multirow{8}{*}{ Highest education } & Did not attend school & $0.00 \%$ \\
\hline & Primary School & $0.22 \%$ \\
\hline & Secondary School & $1.35 \%$ \\
\hline & High School & $11.66 \%$ \\
\hline & College certificate & $6.50 \%$ \\
\hline & College Diploma & $12.33 \%$ \\
\hline & Bachelor's Degree & $29.15 \%$ \\
\hline & Post-graduate qualification & $38.79 \%$ \\
\hline \multirow{5}{*}{ City of residence } & City of Ekurhuleni & $10.31 \%$ \\
\hline & City of Johannesburg & $24.22 \%$ \\
\hline & City of Tshwane & $56.73 \%$ \\
\hline & Sedibeng Municipality & $4.71 \%$ \\
\hline & West Rand Municipality & $4.04 \%$ \\
\hline \multirow{4}{*}{ Type of settlement } & Informal & $1.57 \%$ \\
\hline & Rural & $2.47 \%$ \\
\hline & Suburb & $76.01 \%$ \\
\hline & Township & $19.96 \%$ \\
\hline \multirow{4}{*}{ Property ownership } & Own & $46.86 \%$ \\
\hline & Rent & $43.27 \%$ \\
\hline & Live with friends/relatives & $9.87 \%$ \\
\hline & Homeless & $0.00 \%$ \\
\hline
\end{tabular}

People that answered the questionnaire most frequently reported having one car $(45.2 \%)$, followed by people who did not own a car $(26.7 \%)$, and those with two, three, four, and five or more were $21.6 \%, 4.4 \%, 1.2 \%$, and $0.9 \%$, respectively. Respondents most frequently said they drove a hatchback (45.1\%), followed by a sedan $(31.8 \%)$, van (11.8\%), and SUV (10.8\%). All the motorists interviewed owned either a petrol-fueled car $(81.7 \%)$ 
or diesel car (18.3\%), with no hybrid or electric car owners. In a study conducted in New Zealand, at least $3 \%$ of the respondents owned an electric vehicle [31]. The most common cars had engine sizes of 1.4-1.5 L (36\%), 1.6-1.9 L (29\%), and 2-2.5 L (22\%). It is important to note that over $89 \%$ of the people who responded travel less than $100 \mathrm{~km}$ per day (Table 3).

Table 3. Distance travelled on daily basis.

\begin{tabular}{cc}
\hline Distance & Percentage \\
\hline Less than $20 \mathrm{~km}$ & $32.2 \%$ \\
$20 \mathrm{~km}$ to $49 \mathrm{~km}$ & $36.5 \%$ \\
$50 \mathrm{~km}$ to $99 \mathrm{~km}$ & $20.6 \%$ \\
$100 \mathrm{~km}$ to $149 \mathrm{~km}$ & $7.8 \%$ \\
$150 \mathrm{~km}$ to $199 \mathrm{~km}$ & $1.9 \%$ \\
$200 \mathrm{~km}$ to $249 \mathrm{~km}$ & $1.4 \%$ \\
$250 \mathrm{~km}$ or more & $1.4 \%$ \\
\hline
\end{tabular}

About $92 \%$ of the respondents had an idea that tailpipe gases contribute towards climate change. Surprisingly, $71 \%$ of the respondents knew that there were full-electric vehicles in the South African automotive market. As the footprint and visibility of EVs is very low, proportions of respondents with knowledge of electric vehicles were expected to be low. Around $88 \%$ of the respondents did not know anybody who owns an electric vehicle. This value was also expected to be close to $100 \%$ due to low adoption of EVs in South Africa. Over $40 \%$ of the respondents showed that they were willing to pay extra money to purchase an electric vehicle, while $39 \%$ were not sure, with $21 \%$ of the people not currently in a position to devote extra funds for an electric vehicle. The response to the purchase of EVs, given that they contribute less to air pollution and climate as compared to traditional vehicles, showed that the majority $(76 \%)$ of respondents demonstrated their ambition to buy an electric vehicle based on their environmental integrity.

\subsection{Barriers to Adoption of Electric Cars}

Respondents were presented with key factors that affect adoption of EVs and were asked how likely they would be to buy an electric car given those circumstances (Table 4). It should be noted that the first question had a positive viewpoint, which was likely to affect subsequent answers.

Table 4. Percentages of respondents showing the degree to which they were likely to purchase an electric vehicle based on the current status.

\begin{tabular}{|c|c|c|c|c|c|}
\hline Factor & $1 *$ & $2 *$ & 3 * & 4 * & 5 * \\
\hline It requires no purchase of fuel and thus potentially saves you money in the long run & 53.2 & 34.0 & 7.1 & 4.3 & 1.4 \\
\hline It can only run for a range of around $200 \mathrm{~km}$ before recharging its battery & 23.5 & 34.7 & 12.8 & 20.2 & 8.8 \\
\hline There is an inconvenience of recharging a battery when it runs out & 15.7 & 29.9 & 14.7 & 27.3 & 12.4 \\
\hline It has to be charged up to $8 \mathrm{~h}$ at home for a full charge & 15.7 & 25.4 & 15.7 & 28.0 & 15.2 \\
\hline $\begin{array}{c}\text { Currently there are limited quick (up to } 30 \text { minutes for } 80 \% \text { charge) public charging } \\
\text { stations in South Africa }\end{array}$ & 16.4 & 30.4 & 17.3 & 25.4 & 10.5 \\
\hline It currently comes only as a hatchback in the South African market & 18.5 & 40.9 & 17.1 & 17.1 & 6.4 \\
\hline Current models in the South African market have a maximum speed of $150 \mathrm{~km} / \mathrm{h}$ & 26.3 & 39.4 & 15.5 & 13.8 & 5.0 \\
\hline $\begin{array}{c}\text { It carries warranty of } 8 \text { years or } 150,000 \mathrm{~km} / 6 \text { years or } 100,000 \mathrm{~km} \text { depending on the } \\
\text { make of the car }\end{array}$ & 31.6 & 46.6 & 10.7 & 7.8 & 3.3 \\
\hline It currently costs over USD 30,000 to buy a battery electric vehicle in South Africa & 7.4 & 20.9 & 17.8 & 30.2 & 23.8 \\
\hline $\begin{array}{l}\text { It currently costs over USD } 7000 \text { to buy the battery pack if faulty after expiry } \\
\text { of warranty }\end{array}$ & 8.6 & 17.3 & 13.3 & 28.7 & 32.1 \\
\hline $\begin{array}{l}\text { One might need an extra normal car during emergencies that require driving for } \\
\text { more than } 200 \mathrm{~km} \text { or when your battery is flat }\end{array}$ & 9.1 & 23.6 & 12.2 & 28.9 & 26.3 \\
\hline Average & 20.5 & 31.2 & 14.0 & 21.1 & 13.2 \\
\hline
\end{tabular}

* 1 = (very likely); 2 = (likely); 3 = (neither likely nor unlikely); 4 = (unlikely); $5=$ (very unlikely). 
Respondents felt strongly that they would buy an electric vehicle if it would save them money in the long run. Around $87 \%$ of the people chose the combination of category 1 and category 2 (Table 4). These results are in contradiction with the findings recorded in Tsang et al. [32], which stated that consumers tend not to be intrigued by future long-term savings but rather interested in current financial savings as conditions in the future are uncertain. However, a study conducted by Krupa \& et al. [27] in the US showed $86 \%$ satisfaction with the fact that plug-in hybrid electric vehicles (PHEVs) would make them save monthly spending in the future. It can be noted that consumers are likely to save money as the electricity needed to propel an electric vehicle for $100 \mathrm{~km}$ is by far less expensive than the required diesel or petrol to cover the same distance. Additionally, EVs have few moving parts, which makes their maintenance comparatively cheaper compared to ICE cars [33]. There are no significant differences at both $5 \%$ and $10 \%$ significance levels across all the demographic factors (Table 5, column c).

Table 5. Chi-square tests between demographic factors and factors that influence electric vehicle absorption.

\begin{tabular}{|c|c|c|c|c|c|c|c|c|c|c|c|c|c|}
\hline Factors & $\mathbf{a}^{+}$ & $\mathbf{b}^{+}$ & $c^{+}$ & $d^{+}$ & $\mathrm{e}^{+}$ & $f^{+}$ & $\mathrm{g}^{+}$ & $\mathbf{h}^{+}$ & $i^{+}$ & $\mathrm{j}^{+}$ & $\mathbf{k}^{+}$ & $1^{+}$ & $\mathrm{m}^{+}$ \\
\hline Age & 0.229 & 0.323 & 0.430 & 0.240 & 0.116 & $0.014 * *$ & 0.402 & 0.672 & $0.074 *$ & 0.320 & 0.124 & 0.163 & $0.000 * *$ \\
\hline Gender & 0.118 & 0.104 & 0.445 & 0.568 & 0.670 & 0.408 & 0.898 & 0.997 & 0.303 & 0.238 & 0.807 & 0.127 & $0.009^{* *}$ \\
\hline Education & $0.088 *$ & 0.732 & 0.603 & 0.753 & 0.805 & 0.216 & 0.464 & 0.373 & 0.219 & 0.522 & 0.521 & 0.309 & 0.971 \\
\hline Region & 0.749 & 0.786 & 0.972 & 0.337 & 0.151 & 0.005 & 0.040 & 0.151 & 0.301 & 0.210 & 0.269 & 0.402 & 0.247 \\
\hline Settlement type & 0.275 & 0.425 & 0.372 & 0.495 & $0.034 * *$ & 0.137 & 0.065 * & 0.490 & 0.397 & 0.726 & $0.057 *$ & 0.101 & 0.155 \\
\hline $\begin{array}{l}\text { Property } \\
\text { ownership }\end{array}$ & 0.171 & 0.172 & 0.256 & 0.295 & $0.027^{* *}$ & 0.295 & 0.571 & $0.090 *$ & 0.249 & 0.022 & 0.969 & 0.475 & 0.549 \\
\hline $\begin{array}{c}\text { Type of car } \\
\text { driven } \\
\text { Daily }\end{array}$ & $0.006^{* *}$ & 0.053 & 0.160 & 0.475 & 0.845 & 0.215 & 0.116 & $0.017^{* *}$ & 0.109 & 0.687 & 0.041 & 0.211 & 0.443 \\
\hline $\begin{array}{c}\text { commuting } \\
\text { distance }\end{array}$ & 0.765 & 0.798 & 0.880 & 0.102 & 0.534 & 0.689 & 0.450 & 0.836 & $0.093 *$ & $0.032 * *$ & 0.787 & 0.872 & 0.962 \\
\hline $\begin{array}{l}\text { Awareness of } \\
\text { climate change }\end{array}$ & 0.793 & 0.296 & 0.622 & 0.128 & 0.778 & 0.120 & 0.235 & 0.933 & 0.962 & 0.966 & 0.201 & 0.328 & 0.624 \\
\hline
\end{tabular}

${ }^{+} \mathrm{a}=$ willingness to invest in environmentally friendly car; $\mathrm{b}=$ EVs contribute less to air pollution and climate change; $\mathrm{c}=\mathrm{EVs}$ save money in the long run through non-purchase of fuel; $\mathrm{d}=\mathrm{EVs}$ travel up to $150 \mathrm{~km}$ per charge; $\mathrm{e}=$ EVs require periodic charging; $\mathrm{f}=\mathrm{it}$ takes up to $8 \mathrm{~h}$ to fully charge an electric vehicle battery; $\mathrm{g}=$ there are currently limited quick-charging stations in South Africa; $\mathrm{h}=$ there is less of a variety of EVs; i = current EVs have a maximum speed of up to $150 \mathrm{~km} / \mathrm{hr} ; \mathrm{j}=$ electric vehicle batteries have warranty of 6 to 8 years; $\mathrm{k}=$ it costs over USD 30,000 to buy an electric vehicle in South Africa; 1 = a battery pack for an electric vehicle costs over USD 7000 outside warranty; $\mathrm{m}=$ consumers might need to have an extra normal car to compensate for an electric vehicle in South Africa. ${ }^{* *}$ (significant at $5 \%) .{ }^{*}$ (significant at $\left.10 \%\right)$.

Most of the respondents were not bothered about the current driving range of electric cars, with over $58 \%$ demonstrating their willingness to purchase a car based on that condition. This may be because most of the respondents (89\%) traveled daily distances of less than $100 \mathrm{~km}$, and thus would not be inconvenienced by that driving range. In contrast, a study in China by He et al. [34] showed that perceived risk associated with electric vehicle technology had a negative on adoption. It has to be noted that some studies show that the problem of range limitation in EVs increased anxiety for drivers, which made them highly conservative in their trip planning [32]. This caused owners of EVs to travel less distance than they would have if owning a car with no limitation, and, hence, resulted in a negative driver experience. According to Bonges and Lusk [35], low density of charging stations is the primary cause of range anxiety, and this can only be solved through investing in the charging infrastructure. Huang and Qian [36] also stated that extending the driving range of EVs to long distances will increase consumer satisfaction. Since it takes too long to obtain a full charge, increasing battery density is a viable option that innovators should look into, especially if EVs would be used for long-distance travel.

The idea of charging your vehicle on a regular basis depending on the level of the battery can be an inconvenience to other people. This necessitates some change of habits and requires some form of discipline. One could easily forget to charge the battery even if one has been warned by the electronic system present in the car. The idea of not being able to drive to work due to a flat battery is a constraint on the adoption of EVs, because home chargers are mostly not fast enough to enable one to attend to this kind of circumstance. In the survey, the numbers were split with $45.6 \%$ still in favor of purchasing the electric vehicle 
given this condition, while a considerable proportion of people $(39.7 \%)$ were not in favor of regular charging (Table 4). Furthermore, there were significant differences between the settlement type and property ownership ( $p$ value $<0.05$ ), with over $38 \%$ (contingency table) of the population not willing to buy an electric vehicle living in suburbs and townships (Table 5, column e).

Most of the home charging stations that are sold with EVs in South Africa are standard chargers that can take between 6 and $8 \mathrm{~h}$ for a full recharge. The respondents were not satisfied with this condition, with $43.2 \%$ saying that it was a major constraint to their potential purchase of an electric vehicle, while $41.1 \%$ demonstrated no concern about the issue (Table 4). This current feature made it undesirable for many, who would have compared this with re-fueling of an ICE vehicle, which takes less than $10 \mathrm{~min}$. Other methods, such as battery swaps, have been suggested in an effort to find a solution for this problem, while fast-charging technology has been in development in major companies with future charging of up to $15 \mathrm{~min}$ [32]. The study by Ghasri et al. [15] in Australia indicated that a significant number of respondents preferred low recharging times.

Respondents in the Gauteng Province were not sensitive to the fact that all the cars in the South African market are compact vehicles with limited space. Around $59 \%$ of the people stated that they would buy electric cars even if there was limited choice in terms of vehicle classes. The results are in agreement with previous studies by Ghasri et al. [15]. It is highly surprising, as the information on car ownership showed that many respondents had cars with relatively large space, with only $45 \%$ driving hatchbacks. Given also that in South Africa most families are composed of more than four people, the choice of a compact car might be highly influenced by affordability. The results of Chi-square tests showed significant results ( $p$ value $=0.017$ ) (Table 5, column h) for the type of car driven, with 70\% (contingency table) of people driving hatchbacks willing to buy, while $41 \%$ (contingency table) of people driving SUVs were unwilling to buy EVs because they mostly come as compact vehicles in the current market.

The fact that EVs in the market were perceived to have a maximum top speed of $150 \mathrm{~km} / \mathrm{hr}$ was not a major concern for most respondents $(66 \%)$. There were a few $(20 \%)$ who would prefer a car with high top speed or better performance. The fact that the performance of EVs was viewed negatively by most consumers in the study by Hardman et al. [37] is in slight contradiction with the findings of this study. South African motorists might perceive a top speed of $150 \mathrm{~km} / \mathrm{hr}$ as high performance based on the fact that the maximum speed allowed in the country is $120 \mathrm{~km} / \mathrm{hr}$. Other studies also state that consumers find high-performing cars more desirable and are willing to pay extra for that high acceleration capability [32,37].

Generally, EVs have more warranty than ICE vehicles, with some warranties being up to 10 years in other countries. In the South African market, warranties of up to 8 years are present, which gives motorists satisfaction that any battery-pack failure in that period will be fixed by the manufacturer. Over $75 \%$ of the respondents showed appreciation of the high warranties. In contrast, a majority (over $60 \%$ ) felt that exorbitant prices of batteries beyond the warranty lifecycle was a major constraint to purchasing EVs. The results of the Chi-square test showed that daily commuting distance results were significant at $5 \%$, with $p$ value of 0.032 (Table 5 , column $\mathrm{j}$ ).

Respondents were likely not to purchase an electric vehicle given their current cost in South Africa. More than $54 \%$ of the people were unlikely to buy either the Nissan Leaf or BMW i3 (>USD 40,000), which were the EVs that were in the market due to their purchase price. Less than $30 \%$ of the respondents were likely to buy at the current price. The study is in line with the results obtained in China by He et al. [34], which showed that high-price EVs negatively affect consumer purchases. It can be deduced that, since ICE cars of the same size and specifications are relatively cheaper, costing less than USD 20,000, consumers find it too expensive to own an electric vehicle. The main reason for this cost difference is attributed to the prices of rechargeable battery packs [33]. In a study by Zhu [30] in New Zealand, $64 \%$ of respondents stated that current prices of EVs prevent them from 
adopting this technology. According to Ślusarczyk [38], battery prices are projected to drop drastically in the future, which would result in price parity with ICE vehicles beyond 2024.

Since there are a lot of uncertainties surrounding the use of EVs, it is stated that households would be encouraged to buy a secondary vehicle. Studies in Europe show that most households with an electric vehicle have multiple vehicles [36]. Most respondents $(55 \%)$ showed dissatisfaction with the condition, while some $(32 \%)$ would consider having multiple cars (Table 4). The results of the Chi-square tests also showed significant differences between age groups and gender, with majority of the people below 45 years old showing a positive bias while respondents over 45 years showed dissatisfaction with the possibility of owning an extra vehicle (Table 5, column m). A greater proportion of female versus male respondents also showed negative bias towards purchasing of EVs based on this variable. In South Africa, there is electricity uncertainty caused by scheduled load shedding conducted by the power producer, as well as unplanned regular electricity blackouts caused by malfunctioning old infrastructure. This can cause major challenges for households that need to charge their only car overnight in preparation for daily commuting.

\section{Conclusions}

Electric vehicle technology is considered "disruptive" and requires a substantial modification in consumer behavior, as its way of operating differs significantly to that of an internal combustion engine vehicle [6]. This study investigated consumers' responses to some of the factors that are unique to electric vehicle technology. It was discovered that the respondents had a high willingness to purchase an electric vehicle, with an average percentage of slightly over $50 \%$. The respondents were satisfied with the fact that there was a possibility of reducing their monthly running costs of a vehicle in future if they bought an electric vehicle. The issue of EVs having a limited range did not seem to be a constraint to the respondents, maybe because close to $90 \%$ of respondents traveled less than $100 \mathrm{~km}$ per day. The issues of having limited quick-charge stations around the country and limited vehicle variety did not have a negative effect on their willingness to consider buying an electric vehicle. They also showed appreciation for the high warranty on a battery. The main factors that yielded unwillingness to purchase an electric vehicle were the issue of high purchase price of the vehicle and high battery costs. The other main constraint was the one that indicated the possibility of owning an alternative vehicle in cases of emergencies and electricity blackouts. Based on their affordability and other social circumstances, the willingness to buy EVs varies, and technological advancement has a role to play to increase their rate of absorption in the market. The results from this pilot study show the need for the South African government to implement policies that would improve the uptake of EVs in the market.

Funding: This research was funded by the Agricultural Research Council (South Africa).

Acknowledgments: Authors thank all the colleagues from the Agricultural Research Council who assisted in the collection of data. Thomas Fyfield is thanked for editing this manuscript.

Conflicts of Interest: The authors declare no conflict of interest.

\section{References}

1. Pachauri, R.K.; Meyer, L.A. Climate Change 2014: Synthesis Report. Contribution of Working Groups I, II and III to the Fifth Assessment Report of the Intergovernmental Panel on Climate Change; IPCC: Geneva, Switzerland, 2014. Available online: https: //www.ipcc.ch/site/assets/uploads/2018/05/SYR_AR5_FINAL_full_wcover.pdf (accessed on 20 November 2018).

2. Stocker, T.F.; Qin, D.; Plattner, G.-K.; Tignor, M.; Allen, S.K.; Boschung, J.; Nauels, A.; Xia, Y.; Bex, V.; Midgley, P.M. Climate Change 2013: The Physical Science Basis. Contribution of Working Group I to the Fifth Assessment Report of the Intergovernmental Panel on Climate Change; IPCC: Cambridge, UK; New York, NY, USA, 2013. [CrossRef]

3. Jochem, P.; Babrowski, S.; Fichtner, W. Assessing $\mathrm{CO}_{2}$ emissions of electric vehicles in Germany in 2030. Transp. Res. Part A Policy Pract. 2015, 78, 68-83. [CrossRef]

4. Moeletsi, M.E.; Tongwane, M.I. Projected Direct Carbon Dioxide Emission Reductions as a Result of the Adoption of Electric Vehicles in Gauteng Province of South Africa. Atmosphere 2020, 11, 591. [CrossRef] 
5. Abdul-Manan, A.F.N. Uncertainty and differences in GHG emissions between electric and conventional gasoline vehicles with implications for transport policy making. Energy Policy 2015, 87, 1-7. [CrossRef]

6. Anable, J.; Skippon, S.; Schuitema, G.; Kinnear, N. Who will adopt electric vehicles? A segmentation approach of UK consumers. In Proceedings of the European Council for an Energy Efficient, Hyères, France, 6-11 June 2011; pp. 1015-1026.

7. Becker, T.A.; Sidhu, I.; Tenderich, B. Electric Vehicles in the United States, A New Model with Forecasts to 2030; Center for Entrepreneurship and Technology, University of California: Berkeley, CA, USA, 2009. Available online: http://cet.berkeley.edu/dl/CET_ Technical\%20Brief_EconomicModel2030_f.pdf (accessed on 12 December 2020).

8. Daina, N.; Sivakumar, A.; Polak, J.W. Modelling electric vehicles use: A survey on the methods. Renew. Sustain. Energy Rev. 2017, 68, 447-460. [CrossRef]

9. Ajanovic, A.; Haas, R. Dissemination of electric vehicles in urban areas: Major factors for success. Energy 2016, 115, 1451-1458. [CrossRef]

10. Omahne, V.; Knez, M.; Obrecht, M. Social aspects of electric vehicles research-Trends and relations to sustainable development goals. World Electr. Veh. J. 2021, 12, 15. [CrossRef]

11. Kloess, M. Potentials of Hybrid and Electric Cars to Reduce Energy Consumption and Greenhouse Gas Emissions in Passenger Car Transport-Techno-Economic Assessment and Model-Based Scenarios. Ph.D. Thesis, Technical University of Vienna, Vienna, Austria, 2011.

12. Gustafsson, M.; Svensson, N.; Eklund, M.; Möller, B.F. Well-to-wheel climate performance of gas and electric vehicles in Europe. Transp. Res. Part D Transp. Environ. 2021, 97, 102911. [CrossRef]

13. Morton, C.; Anable, J.; Yeboah, G.; Cottrill, C. The spatial pattern of demand in the early market for electric vehicles: Evidence from the United Kingdom. J. Transp. Geogr. 2018, 72, 119-130. [CrossRef]

14. Un-Noor, F.; Padmanaban, S.; Mihet-Popa, L.; Mollah, M.N.; Hossain, E. A comprehensive study of key electric vehicle (EV) components, technologies, challenges, impacts, and future direction of development. Energies 2017, 10, 1217. [CrossRef]

15. Ghasri, M.; Ardeshiri, A.; Rashidi, T. Perception towards electric vehicles and the impact on consumers' preference. Transp. Res. Part D Transp. Environ. 2019, 77, 271-291. [CrossRef]

16. Jabeen, F.; Olaru, D.; Smith, B.; Braunl, T.; Speidel, S. Acceptability of Electric Vehicles: Findings from a Driver Survey. In Shaping the Future: Linking Research, Policy and Outcomes; Australasian Transport Research Forum: Perth, Australia, 2012.

17. Wan, Z.; Sperling, D.; Wang, Y. China's electric car frustrations. Transp. Res. Part D Transp. Environ. 2015, 34, 116-121. [CrossRef]

18. Wang, F.P.; Yu, J.L.; Yang, P.; Miao, L.X.; Ye, B. Analysis of the barriers towidespread adoption of electric vehicles in Shenzhen China. Sustainability 2017, 9, 522. [CrossRef]

19. Egbue, O.; Long, S. Barriers to widespread adoption of electric vehicles: An analysis of consumer attitudes and perceptions. Energy Policy 2012, 48, 717-729. [CrossRef]

20. Thiel, C.; Tsakalidis, A.; Jäger-Waldau, A. Will electric vehicles be killed (again) or are they the next mobility killer app? Energies 2020, 13, 1828. [CrossRef]

21. International Energy Agency. Global EV Outlook 2021: Accelerating Ambitions Despite the Pandemic. 2021. Available online: https:/ / iea.blob.core.windows.net/assets/ed5f4484-f556-4110-8c5c-4ede8bcba637/GlobalEVOutlook2021.pdf (accessed on 20 November 2018).

22. Gauteng Info. Gauteng Information. 2018. Available online: https://www.gauteng-info.co.za/provinces/info (accessed on 29 November 2018).

23. Eskom. Understanding Electricity. 2021. Available online: http://www.eskom.co.za/AboutElectricity/ElectricityTechnologies / Pages/Understanding_Electricity.aspx (accessed on 20 November 2018).

24. Raw, B.; Jack, R. Electric Vehicles 2020: Market Intelligence Report. 2020. Available online: https:/ /www.greencape.co.za/assets/ Uploads/ELECTRIC_VEHICLES_MARKET_INTELLIGENCE_REPORT_25_3_20_WEB.pdf (accessed on 20 November 2018).

25. Electromaps. Charging Station on South Africa. 2021. Available online: https://www.electromaps.com/en/charging-stations/ south-africa (accessed on 26 August 2021).

26. Jabeen, F. The Adoption of Electric Vehicles: Behavioural and Technological Factors. Ph.D. Thesis, The University of Western Australia, Perth, Australia, 2016.

27. Krupa, J.S.; Rizzo, D.M.; Eppstein, M.J.; Lanute, D.B.; Gaalema, D.E.; Lakkaraju, K.; Warrender, C.E. Analysis of a Consumer Survey on Plug-In Hybrid Electric Vehicles. Transp. Res. Part A Policy Pract. 2014, 64, 14-31. [CrossRef]

28. StatisticsHowTo. Cronbach's Alpha: Simple Definition Use and Interpretation. 2014. Available online: https://www. statisticshowto.com/cronbachs-alpha-spss/ (accessed on 12 November 2018).

29. Tavakol, M.; Dennick, R. Making sense of Cronbach's alpha. Int. J. Med. Educ. 2011, 2, 53-55. [CrossRef]

30. Lehohla, P. Census 2011: Provincial Profile: Gauteng; Statistics South Africa: Pretoria, South Africa, 2014. Available online: http:/ / www.statssa.gov.za/publications / Report-03-01-76/Report-03-01-762011.pdf (accessed on 23 November 2018).

31. Zhu, J. Analysis of New Zealand Specific Electric Vehicle Adoption Barriers and Government Policy; Victoria University of Wellington: Wellington, New Zealand, 2016. Available online: http:/ / hdl.handle.net/10063/6190 (accessed on 20 November 2018).

32. Tsang, F.; Pedersen, J.S.; Wooding, S.; Potoglou, D. Bringing the electric vehicle to the mass market a review of barriers, facilitators and policy interventions. Work. Pap. 2012, 1-77. Available online: https://www.rand.org/pubs/working_papers/WR775.html (accessed on 20 November 2018). 
33. Bessenbach, N.; Wallrap, S. Why do Consumers Resist buying Electric Vehicles? 2013, p. 137. Available online: http:/ / studenttheses. cbs.dk/bitstream/handle/10417/4329/nadine_bessenbach_og_sebastian_wallrapp.pdf (accessed on 20 November 2018).

34. He, X.; Zhan, W.; Hu, Y. Consumer purchase intention of electric vehicles in China: The roles of perception and personality. J. Clean. Prod. 2018, 204, 1060-1069. [CrossRef]

35. Bonges, H.A.; Lusk, A.C. Addressing electric vehicle (EV) sales and range anxiety through parking layout, policy and regulation. Transp. Res. Part A Policy Pract. 2016, 83, 63-73. [CrossRef]

36. Huang, Y.; Qian, L. Consumer preferences for electric vehicles in lower tier cities of China: Evidences from south Jiangsu region. Transp. Res. Part D Transp. Environ. 2018, 63, 482-497. [CrossRef]

37. Hardman, S.; Shiu, E.; Steinberger-Wilckens, R. Comparing high-end and low-end early adopters of battery electric vehicles. Transp. Res. Part A Policy Pract. 2016, 88, 40-57. [CrossRef]

38. Ślusarczyk, B. Electromobility for sustainable transport in Poland. In Energy Transformation Towards Sustainability; Tvaronavičienė, M., Ślusarczyk, B., Eds.; Elsevier: Amsterdam, The Netherlands, 2019; pp. 199-218. 